\title{
The Impact of Emphysema on Chronic Obstructive Pulmonary Diseases
}

Juan P. de Torres, $M D^{1}$ and Ciro Casanova, MD²

${ }^{1}$ Pulmonary Department, Clinica Universidad de Navarra, Pamplona, Spain, and ${ }^{2}$ Pulmonary Department, Hospital Universitario Ntra. Sra. de Candelaria, Tenerife, Spain

\section{ABSTRACT}

Emphysema is defined as an abnormal and permanent enlargement of the air spaces distal to the terminal bronchioles that is accompanied by destruction of the air space walls, with no obvious fibrosis (i.e. there is no fibrosis visible to the naked eye) and it is usually associated to tobacco smoking.

Although it is included in the pathological definition of chronic obstructive pulmonary disease (COPD), not all COPD patients have emphysema and its impact on the clinical presentation and the natural history of the disease is variable.

The present review will cover the prevalence of emphysema in COPD patients, its impact on the clinical presentation, association with comorbidities and the main outcomes of the disease: exacerbations, lung function decline and mortality. In this review, we will only evaluate the relationship of tobacco-related emphysema with COPD. (BRN Rev. 2017;3:235-46) Corresponding author: Juan P. de Torres, jupa65@hotmail.com

Key words: COPD. Emphysema 


\section{EMPHYSEMA DEFINITION AND NONINVASIVE DETECTION}

Chronic obstructive pulmonary disease (COPD) is a heterogeneous disease not only in its clinical but also in its pathological presentation. The pathological definition of COPD includes changes at the airway level (predominantly small airways: chronic bronchitis), lung parenchyma (emphysema) and the vascular compartment (vascular remodelling) ${ }^{1}$. The contribution of each of these processes is highly variable, depending on the intensity, type of toxic inhalation (mainly tobacco) and individual's susceptibility.

Emphysema is defined as an abnormal and permanent enlargement of the air spaces distal to the terminal bronchioles that is accompanied by destruction of the air space walls, with no obvious fibrosis (i.e., there is no fibrosis visible to the naked eye) ${ }^{1}$. There are three pathological types of emphysema (Fig. 1): centrilobular (most commonly associated to tobacco), panacinar (usually associated to alpha-1-antitrypsin deficiency [AAT]) and paraseptal (that could occur associated with the previous types or alone, and that is usually associated to spontaneous pneumothorax $)^{2}$. Emphysema can contribute to airflow limitation (AL) through the destruction of alveolar walls, loss of airway tethering resulting in decreased elastic recoil and airway collapse.

Technological advances in software and computed tomography $(\mathrm{CT})$ techniques currently allow a precise assessment of the presence, extent and distribution of emphysema ${ }^{3}$. The

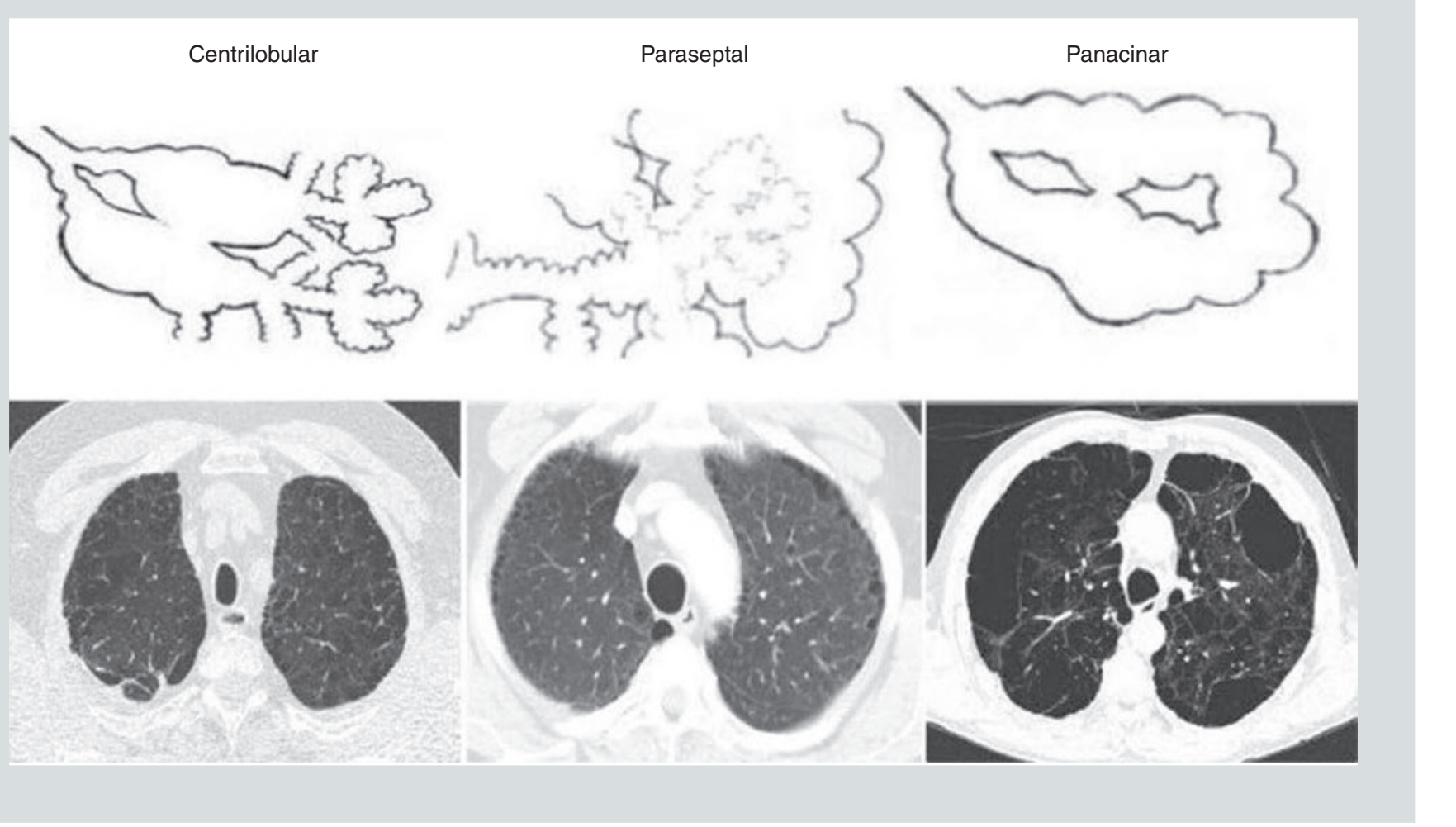

FIgURE 1. Visual and computed tomography (CT) description of the three types of emphysema. 
presence and proportion of low attenuation areas (LAA) in CT scans (Fig. 2), correlate well with pathology ${ }^{4}$ and lung function ${ }^{5}$. Madani et al. ${ }^{4}$ found the strongest correlation with macroscopy with a threshold of $-970 \mathrm{HU}(\mathrm{r}=0.543$, $\mathrm{p}<0.001)$ and that with microscopy was observed at -960 and $-970 \mathrm{HU}$, depending on the index considered $(\mathrm{r}=0.592, \mathrm{p}<0.001$ and $r=-0.546, p<0.001$, respectively). For percentiles, 1st percentile showed the strongest correlation with both macroscopy $(r=-0.463$, $\mathrm{p}<0.001)$ and microscopy $(\mathrm{r}=-0.573, \mathrm{p}<0.001$ and $r=0.523, p<0.001$ for each microscopic measurement). This radiological technique has been used in COPD patients to determine if a patient is a candidate for lung volume reduction techniques ${ }^{6}$ or to monitor the response to augmentation therapy in those with severe AAT$^{7}$. The National Emphysema Treatment Trial (NETT) classification of visual severity of emphysema, is the most widely used (Fig. 3).

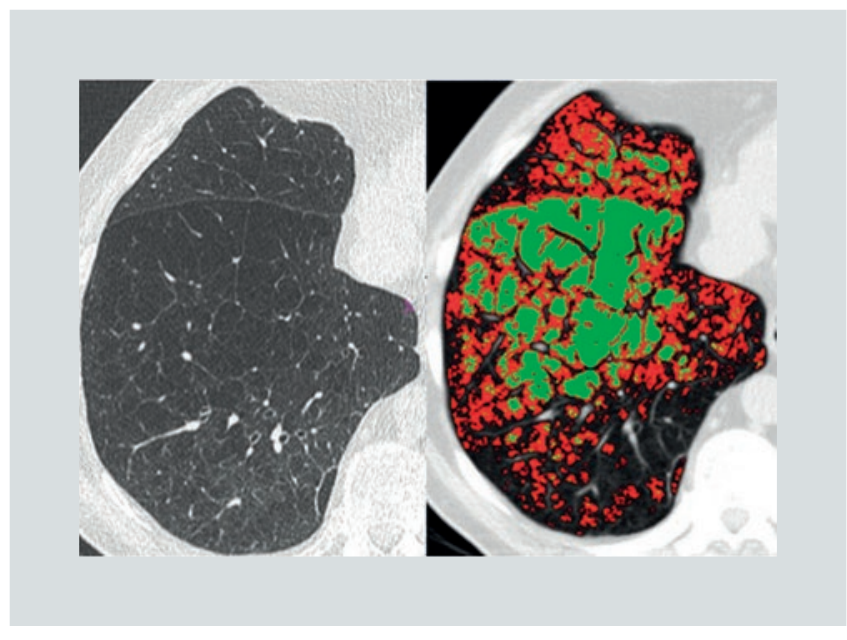

FIgURE 2. Low attenuation areas (LAA) detection in a chest computed tomography (CT) scan. Colours denote different grades of LAA $(<-960 \mathrm{HU})$ density, ranging from high (green) to less intense (red).

\section{Prevalence of emphysema in COPD patients and its impact on symptoms}

Several studies have explored the prevalence and distribution of emphysema in COPD patients. Nakano et al. ${ }^{8}$ studied a rather small sample of $(n=73)$ male COPD patients and

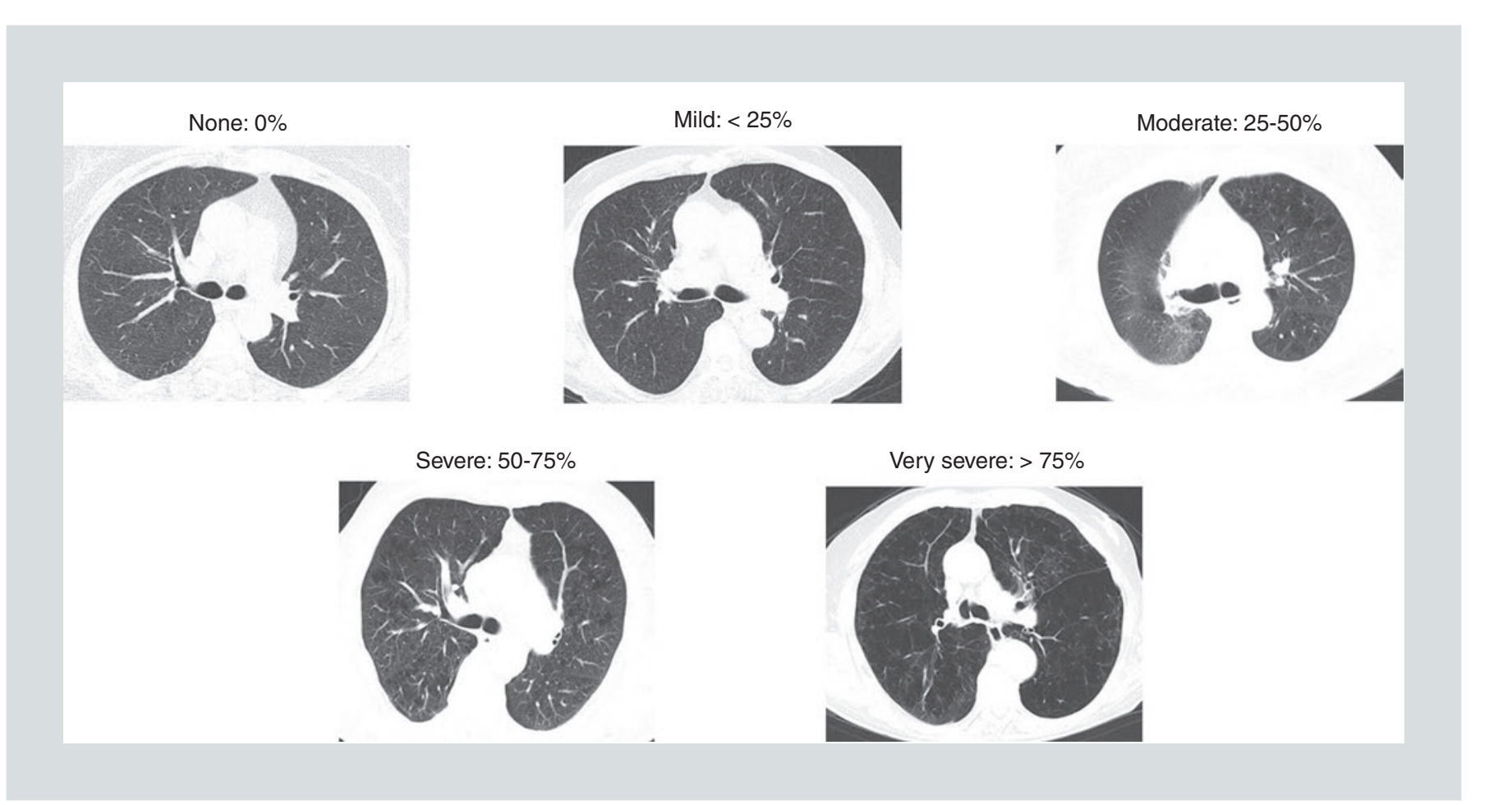

FIGURE 3. National emphysema treatment trial (NETT) classification of the extent of emphysema in computed tomography (CT) scans, expressed as different percentages of lung volume. 
observed that LAA are more often distributed in the upper and inner parts of the lungs. They also reported that the contribution of the central distribution to pulmonary function tests may be greater than the peripheral distribution. Later, Mair et al. ${ }^{9}$ evaluated a larger population of COPD patients (this time also including females), confirming that emphysema was found predominantly in the upper/core zone and that this distribution related best to clinical features such as lower forced expiratory volume in the $1^{\text {st }}$ second $\left(\mathrm{FEV}_{1}\right)$, body mass index $(\mathrm{BMI})$ and higher body mass index $(\mathrm{B})$, obstruction $(\mathrm{O})$, dyspnoea (D) and exercise (E) (i.e., BODE) index and Medical Research Council (MRC) dyspnoea scale. Using multiple liner regression age, sex and emphysema severity were independently related to upper/lower distribution.

De Torres et al..$^{10}$ investigated the impact of emphysema presence and distribution in a specific population of COPD patients with mild to moderate degree of AL. They found that the degree of emphysema in a population of 115 patients regularly followed in an outpatient clinic, was mild and mainly distributed in the upper and core regions. They concluded that, although the presence of emphysema has an impact on physiology, its severity and distribution seem to have little impact on other clinical parameters.

Recently, the Canadian Cohort Obstructive Lung Disease (CanCOLD) study from Canada ${ }^{11}$ evaluated the presence of emphysema in a large population, including 408 healthy never smokers, 502 healthy ever-smokers and 451 COPD patients. They found that prevalence of emphysema was $11 \%$ in healthy never smokers, $30 \%$ in healthy ever smokers and 36\%, 50\% and $56 \%$ in patients with mild, moderate or severe/very severe COPD, respectively. They noted that the presence of emphysema was independently associated with cough, chronic phlegm production, wheeze, MRC dyspnoea scale $\geq 2$, COPD Assessment Test (CAT) score $\geq 10$ and an exacerbation frequency $\geq 2$ in the first year of follow-up. Most of the patients (92\%) had mild to moderate degree of AL.

\section{Impact of emphysema on comorbidities}

\section{EMPHYSEMA AND CARDIOVASCULAR DISEASE}

The presence of emphysema in COPD is usually associated not only with airway limitation but also with lung hyperinflation, which implies an increased volume over the tidal breathing range and increase in functional residual capacity (FRC) leading to high intrinsic positive end-expiratory pressure $(\mathrm{PEEPi})^{12}$. These physiological changes explain why COPD patients with emphysema usually complain of dyspnoea and exercise limitation ${ }^{1}$. There is evidence that the cardiovascular (CV) impact of emphysema could be mediated via several different pathophysiological mechanisms:

- Lung hyperinflation at rest, can significantly affect heart size and function by causing intrathoracic hypovolemia and small end-diastolic dimensions of left and right chambers. These chambers could also be mechanically compressed causing end-diastolic stiffness ${ }^{13}$.

- During exercise, emphysematous patients develop "dynamic hyperinflation" further restraining the already poor cardiac function. Vassaux et al. ${ }^{14}$ proved that dynamic 
hyperinflation is inversely associated with peak oxygen pulse (an indirect measure of cardiac stroke volume), while Come et al. ${ }^{15}$ showed that lung volume reduction surgery (LVRS) could significantly improve oxygen pulse (and exercise capacity) by deflating the lungs ${ }^{15}$.

- Finally, in many COPD patients, there is important skeletal muscle atrophy (sarcopenia) that occurs primarily in emphysematous patients. Such peripheral muscle depletion has been related by Teopompi et al. ${ }^{16}$ with poor cardiovascular response $(\mathrm{CV})$ to exercise and to leg fatigue independently of the degree of airway obstruction.

\section{EMPHYSEMA AND LUNG CANCER RISK}

Radiologically detected emphysema has been recognized as an independent risk factor for lung cancer ${ }^{17,18}$. The combination of COPD and emphysema in active or former smokers significantly multiplies this risk, making this group as a potential ideal target for lung cancer screening programs $s^{19}$. Several mechanisms have been described $^{20}$ to explain this lethal association:

1. Stimulation of the basal membrane-associated stem cells at the alveolar level that in an attempt to repair the damage produced by chronic inflammation and oxidative stress, may mutate to abnormal "malignant cells".

2. Chronic retention of carcinogens leading to the generation of cancer.

3. Common genetic risk factors (cholinergic receptor nicotinic alpha subunit $3 / 5$ (CHRNA3/5), hedgehog-interacting protein (HHIP), telomerase reverse transcriptase
(TERT), deoxyribonucleic acid (DNA) hypermethylation, micro ribonucleic acids (miRNAs)) that express as diseases running a parallel course.

In an effort to help identify those COPD patients at higher risk for lung cancer development, our group developed and validated the COPD Lung Cancer Screening Score (COPD-LUCSS) ${ }^{21}$. The COPD-LUCSS includes age, pack-years history, BMI and presence of radiological emphysema. It goes from $0-10$ and a score $\geq 7$ points increased the risk of developing a lung cancer 3 times compared with those with a score of 0-6 points. To simplify the identification of highrisk patients, the same authors also described the COPD-LUCSS diffusing capacity of carbon monoxide $\left(\mathrm{DL}_{\mathrm{CO}}\right)$ replacing radiological emphysema by a $\mathrm{DL}_{\mathrm{CO}}<60 \%$ avoiding the need to have a baseline CT to determine the presence of emphysema ${ }^{22}$.

\section{EMPHYSEMA: ASSOCIATION WITH MALNUTRITION AND OSTEOPOROSIS}

Since the graphic description made by Netter in the Ciba Symposium pictorial book ${ }^{23}$, the emphysematous COPD patient has been traditionally associated with a thin frail individual with low BMI and with loss of muscle mass, now well represented by a low free-fat mass index (FFMI). Several studies have demonstrated an inverse relationship between the extent of emphysema and the degree of malnutrition represented by BMI and specially $\mathrm{FFMI}^{24}$. Although not well established for all patients, some data suggest that nutritional support in COPD patients who are malnourished, may have a positive impact on exercise capacity and quality of life of these patients ${ }^{25}$. 
Impact in the clinical presentation of COPD patients

- Worse lung function

- Worse diffusing capacity

- Higher degree of dyspnea

- Lower exercise capacity

- Worse quality of life

- Higher number of exacerbations

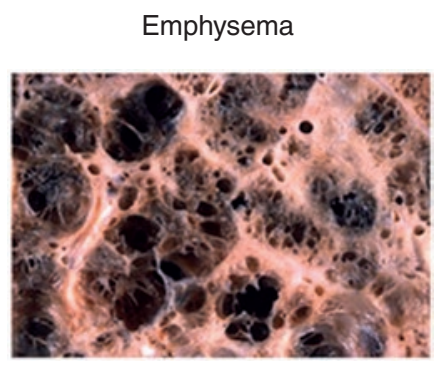

Association with comorbidities in COPD patients

- Higher lung cancer risk

- Worse CV performance

- Higher degre of malnutrition

- Higher prevalence of osteoporosis

FIgURE 4. Impact of emphysema presence in the clinical presentation and the risk of associated comorbidities in chronic obstructive pulmonary disease (COPD) patients.

CV: cardiovascular

The relationship between emphysema and osteoporosis is scanty but increasing as more studies address $i^{26}$. Bon et al. ${ }^{27}$ confirmed that the degree of emphysema in COPD patients is the most important factor associated with the presence of osteoporosis independently of other predictors such as age, gender, tobacco smoking and BMI. Several pathways have been proposed in trying to explain the association of these two matrix degradation processes at different locations of COPD patients, but more research is still needed to try to elucidate the nexus ${ }^{28}$.

In summary, data suggest that emphysema presence, severity and distribution in COPD patients has an inverse relationship with the degree of airway limitation and diffusing capacity. It also has a negative impact on the clinical presentation of the disease mostly in patients with moderate to very severe airway limitation. The presence of emphysema in COPD patients puts them at higher risk of lung cancer, CV dysfunction, malnutrition and osteoporosis (Fig. 4).

\section{INFLUENCE OF EMPHYSEMA IN THE NATURAL HISTORY OF PATIENTS WITH COPD}

Recently, there have been important advances in the understanding of the natural history of COPD. This has been based, fundamentally, on observational studies of cohorts of patients with $\mathrm{COPD}^{29,30}$ and some population studies ${ }^{31}$, and it has led to important conceptual changes:

- The progression of COPD is heterogeneous ${ }^{29-31}$.

- Most patients remain stable for long periods of time (5 to 8 years $)^{29-32}$

- In a large number of patients, pulmonary developmental disorders, probably acquired in the first years of life, may lead to AL without an accelerated decline in lung function ${ }^{33}$. In addition, the evolution of COPD may be different between spirometric parameters $\left(\mathrm{FEV}_{1}\right)$ and other pulmonary or extrapulmonary factors. In spite of the advances in the knowledge of the evolution of $\mathrm{FEV}_{1}$, the progression in other important parameters of 
the disease remain poorly studied. We need a better characterization of the patients, to better describe the different natural histories of the phenotypes that coexist in COPD ${ }^{34-36}$.

\section{EMPHYSEMA AND LUNG FUNCTION DECLINE}

Several studies based on observational cohorts have shown that emphysema is one of the main factors associated with the decline of $\mathrm{FEV}_{1}$.

However, in addition to being a causal factor, it could also be part of the disease process. Initially, the long-term longitudinal analysis of the BODE cohort showed that a lower BMI was associated with larger $\mathrm{FEV}_{1}$ annual decline $^{29}$. Vestbo et al. ${ }^{31}$, in the Evaluation of COPD Longitudinally to Identify Predictive Surrogate End-points (ECLIPSE) cohort, showed for the first time the importance of the emphysema estimated by CT in the decline of $\mathrm{FEV}_{1}$. Patients who had $>10 \%$ LAA had a significant annual loss of $\mathrm{FEV}_{1}$ with a decrease of $13 \mathrm{ml} / \mathrm{yr}$. Although other factors (current smoker and bronchodilator reversibility) were higher in absolute numbers $(\mathrm{ml} / \mathrm{yr})$, probably emphysema was higher if adjusted by the initial baseline level of $\mathrm{FEV}_{1}$.

Data from the ECLIPSE cohort with three years of follow-up were later confirmed in a smaller Japanese cohort (Hokaido) ${ }^{30}$, but with five years of follow-up. In addition, the role of CT (\% LAA or visual score) or percentage of carbon monoxide transfer factor $\left(\mathrm{K}_{\mathrm{co}}\right)$ was maintained as an independent factor in the prediction of $\mathrm{FEV}_{1}$ decline. Patients who lost more lung function versus those who did not lose had a \% LAA of $25 \%$ and a $\mathrm{K}_{\mathrm{co}}<60 \%$ versus $10 \%$ LAA and $\mathrm{K}_{\mathrm{co}}>70 \%$, respectively.
Recent studies have also shown that the rate of the decline in lung function is independently affected by the regional distribution or the severity of emphysema: more homogeneous distribution of emphysema contributed to an accelerated decline in $\mathrm{FEV}_{1}$ independently of whole-lung emphysema severity ${ }^{37}$.

At this time, only one group has evaluated the longitudinal evolution of hyperinflation through the inspiratory to total lung capacity IC/TLC ratio, observing that it was $0.65 \%$ per year and that it is higher in patients with more dyspnoea (modified MRC [mMRC]), a greater number of comorbidities (Charlson index) and worse $\mathrm{FEV}_{1}^{38}$. In addition, in a new analysis, they observed that the progression of lung hyperinflation (estimated by a reserve volume (RV)/TLC ratio) was associated with frequent exacerbations and a faster $\mathrm{FEV}_{1}$ decline $^{39}$.

Recently, the ECLIPSE cohort longitudinally evaluated the change in CT lung density over 3 years. The severity of objectively defined emphysema worsened over that time (mean decline $-1.13 \mathrm{~g} / 1$ [SE 0.06] per year). The annual decline in lung density was more rapid in women than in men and in current smokers than in former smokers. Circulating levels of the biomarkers surfactant protein D and soluble receptor for advanced glycation end-product (sRAGE) were significantly associated with both baseline lung density and its decline over time. These findings suggest that smoking cessation has the potential to limit further structural deterioration within the lung ${ }^{40}$.

Interestingly, in that study the association between emphysema changes and $\mathrm{FEV}_{1}$ decline was weak. This could be explained by the regional distribution of emphysema: the 
lungs have a ventilation-perfusion ratio relatively high in the upper compared to the lower areas. Therefore, in the hypoventilated areas of the upper lobes, pulmonary emphysema causes lesser pulmonary dysfunction than when is located in the bases. In fact, previous studies have shown that the extent of emphysema presented higher correlations with $\mathrm{DL}_{\mathrm{CO}} \mathrm{AL}$ and lung volumes when it is located in the basal portions of the lungs ${ }^{41,42}$. These data could support the heterogeneity presentation of the disease with different natural histories.

\section{EMPHYSEMA END EXACERBATIONS}

It has been classically thought that patients with COPD and the emphysema phenotype have a lower frequency of exacerbations than those with the chronic bronchitis profile. However, the advances in imaging technology through the use of chest CT have allowed a better characterization of patients with emphysema and a more accurate analysis of the relationship with exacerbations.

Two large multicenter observational studies (ECLIPSE and Chronic Obstructive Pulmonary Disease gene [COPDgene]) have shown that emphysema is a risk factor for exacerbations regardless of the degree of airway limitation expressed by $\mathrm{FEV}_{1}^{43,44}$. Furthermore, this association remained after compared with the thickness of the airway and showed an even stronger association in the large prospective Canadian Cohort of Obstructive Lung Disease (CanCOLD) where unlike previous studies the data were based on unselected individuals from a random sample from the general population ${ }^{11}$.

Interestingly, in the COPDgene study, they observed that the relationship with the exacerbations is not linear and it is necessary to reach an important threshold in the severity of emphysema in order to make evident this association: an emphysema percentage $\geq$ $35 \%$ was associated with a significant increase in exacerbation frequency, with a 1.18-fold change for each $5 \%$ increase in emphysema. The influence of emphysema on exacerbation frequency at lower levels of emphysema, when adjusted for lung function and wall thickness, was less clear. In fact, decreased exacerbation frequency was seen for subjects with 10-35\% emphysema ${ }^{43}$.

Lung hyperinflation and gas trapping may be the main mechanisms that induce the presence of exacerbations ${ }^{45,46}$. Although no studies or pharmacological trials have been designed to specifically evaluate this fact, it has been observed that patients with IC/TLC ratio $<0.25$ o RV/TLC ratio $>50 \%$ have more exacerbations $^{44,46}$. In the NETT study, it was observed that LVRS reduces the frequency of COPD exacerbations and increases the time to first exacerbation ${ }^{47}$. However, this effect was greatest in those subjects with the largest postoperative improvement in $\mathrm{FEV}_{1}$, but changes in lung volumes estimated by a slow vital capacity (VC) and FRC were excluded from the multivariable Cox regression model (to determine whether changes in physiologic variables were associated with exacerbations). The discrepancy could be related with the fact that the NETT study was not designed to evaluate exacerbations and this post-hoc analysis only included those exacerbations that required emergency room assistance or hospitalization ${ }^{47}$.

Finally, we must take into account the issue that the relationship of exacerbations with emphysema could be bidirectional. Tanabe et al. ${ }^{48}$ showed 
that annual changes in CT emphysema parameters were greater in patients with a history of COPD exacerbations, although these data were not replicated in the ECLIPSE cohort ${ }^{49}$.

\section{EMPHYSEMA AND MORTALITY}

About twenty years ago one of the main clinical features of the emphysema phenotype, such as "low weight", was shown to be a predictor of general and respiratory mortality in patients with COPD, independent of $\mathrm{FEV}_{1}{ }^{50}$. This was confirmed by other studies and the risk cutoff point was estimated at a BMI threshold of $<20-21$. Subsequently, another physiological surrogate marker of emphysema such as the lung hyperinflation expressed by the IC/TLC ratio (dubbed inspiratory fraction), also proved to be an independent and superior predictor than the $\mathrm{FEV}_{1}$. Its estimated risk threshold was an IC/TLC ratio $<0.25$, with a three times higher mortality in patients with values below this cut-off point ${ }^{51}$.

More recently, the NETT study made possible the first solid analysis of the impact of CT-determined emphysema on survival of COPD patients ${ }^{52}$. In this cohort, with a significant amount of emphysema and lung hyperinflation, older age, lower BMI, oxygen consumption (in contrast to $\mathrm{PaO}_{2}$ ), and greater lung hyperinflation were associated with an increased risk of death over time. Exercise capacity, quantified in a cardiopulmonary exercise test in contrast to a six-minute walking test (6MWT) distance, proved to be a powerful independent predictor of survival. Diffusing capacity $\mathrm{DL}_{\mathrm{CO}}$ expressed as $\mathrm{K}_{\mathrm{CO}}$ was also a good predictor of mortality but only in the univariable analysis ${ }^{52}$.
Another important finding from that study was the lack of association of the presence of upper lobe predominant emphysema and risk of mortality ${ }^{52}$, something that did happen with lower lobe predominance associated with the presence of centrilobular emphysema. Therefore, it could also be possible that lower-lobe emphysema may represent a phenotypic or pathobiologic variant of emphysema presented as centrilobular ${ }^{53}$.

Subsequent studies ${ }^{54,55}$, with smaller cohorts but longer follow-up time (4 versus 8 years) and with different AL severity observed a significant association of lung attenuation areas low attenuation area (\% LAA) and the prognosis of the disease $\mathrm{e}^{54,55}$. Patient selection and emphysema evaluation criteria (\% LAA) make comparisons between studies difficult.

Haruna et al. ${ }^{54}$ demonstrated in a cohort of men with COPD that the ability of emphysema to predict mortality was independent of age, $\mathrm{FEV}_{1}$, and other predictors associated with the emphysema phenotype such as BMI, RV/TLC and the $\mathrm{K}_{\mathrm{co}}$. However, important factors such as the BODE index and comorbidities were not included in the comparative analysis. Differences in survival of the worst LAA\% quintile (> 30-40\%) were observed only after three years of follow-up. However, unlike the study by Martinez et al. ${ }^{53}$, in this case these authors did not find differences in prognosis according to the location of emphysema (lower versus upper lobes).

Johannessen et al. ${ }^{55}$, have shown that the degree of emphysema predicts all-cause, respiratory and cardiovascular mortality in a population-based sample of subjects with and without COPD. Patients with a degree of emphysema 
$>10 \%$ (LAA) had three years shorter survival than patients with a degree of emphysema $<10 \%$. Unfortunately, as in the previous study, this predictive power was not compared with other prognostic factors related to the phenotype emphysema such as the IC/TLC ratio, $\left(\mathrm{K}_{\mathrm{co}}\right)$ or the BODE index. However, an independent predictive role of thick airway thickness was observed. In addition, the impact on survival of a relatively low degree of emphysema is of great relevance, since it can affect many patients with non-severe AL as it was observed in this study and replicated in the ECLIPSE cohort, where $2 / 3$ of the patients evaluated had this emphysema severity ${ }^{52}$. This finding supports once again the importance of imaging studies for an adequate characterization of COPD patients.

The mechanisms by which emphysema may contribute to premature death include direct physiologic effects of losing lung parenchyma and vasculature. This loss has been related to lung-specific inflammatory markers, such as surfactant protein D and increased neutrophilic inflammatory infiltration ${ }^{56,57}$. This parenchymal loss, will lead to a reduction in the area available for gas exchange, which may lead to hypoxaemia, poor exercise capacity, and reduced functional status. Loss of alveolar walls also contributes to untethering of airways, loss of radial traction forces, and reduction in airway calibre, which may contribute to more rapid $\mathrm{FEV}_{1}$ decline and $\mathrm{AL}^{58}$.

Other mechanisms linking emphysema to allcause mortality include increased susceptibility to lung cancer ${ }^{32}$, pulmonary infections ${ }^{9}$, impaired cardiac function resulting in reduced left ventricular filling and stroke volume ${ }^{59}$, endothelial and microvascular dysfunction of the pulmonary and systemic capillary system and systemic inflammation ${ }^{60}$.

It is now generally recognized that COPD is associated with systemic manifestations that impact on survival, such as skeletal muscle wasting, cachexia, osteoporosis, pulmonary hypertension, ischemic heart disease, and depression ${ }^{61}$. However, it is still unclear whether emphysema predisposes patients with COPD to such systemic manifestations and whether systemic manifestations contribute to the development of emphysema ${ }^{62}$, nor if patients with initial presentation as symptomatic emphysema without airway limitation then progress to spirometric $\mathrm{COPD}^{63}$.

In summary, the degree of emphysema assessed by CT has an impact on the natural history of COPD. It is associated with rapid $\mathrm{FEV}_{1}$ decline, increase of exacerbations and allcause mortality in COPD patients from clinical studies as well as from the general population. This relationship is independent of the severity of AL measured by the $\mathrm{FEV}_{1}$, and possibly not linear with the degree of emphysema itself (at least $>10 \%$ ) according to the outcome (Fig. 5). These data provide evidence that the detection of emphysema on chest CT is of great value in order to adequately characterize COPD patients.

\section{CONCLUSIONS AND MAIN MESSAGE}

Determining the presence, type, distribution and severity of emphysema in COPD patients is important because it could greatly impact on their lung function severity and progression, symptoms severity, natural history and outcomes such as exacerbations and mortality. 


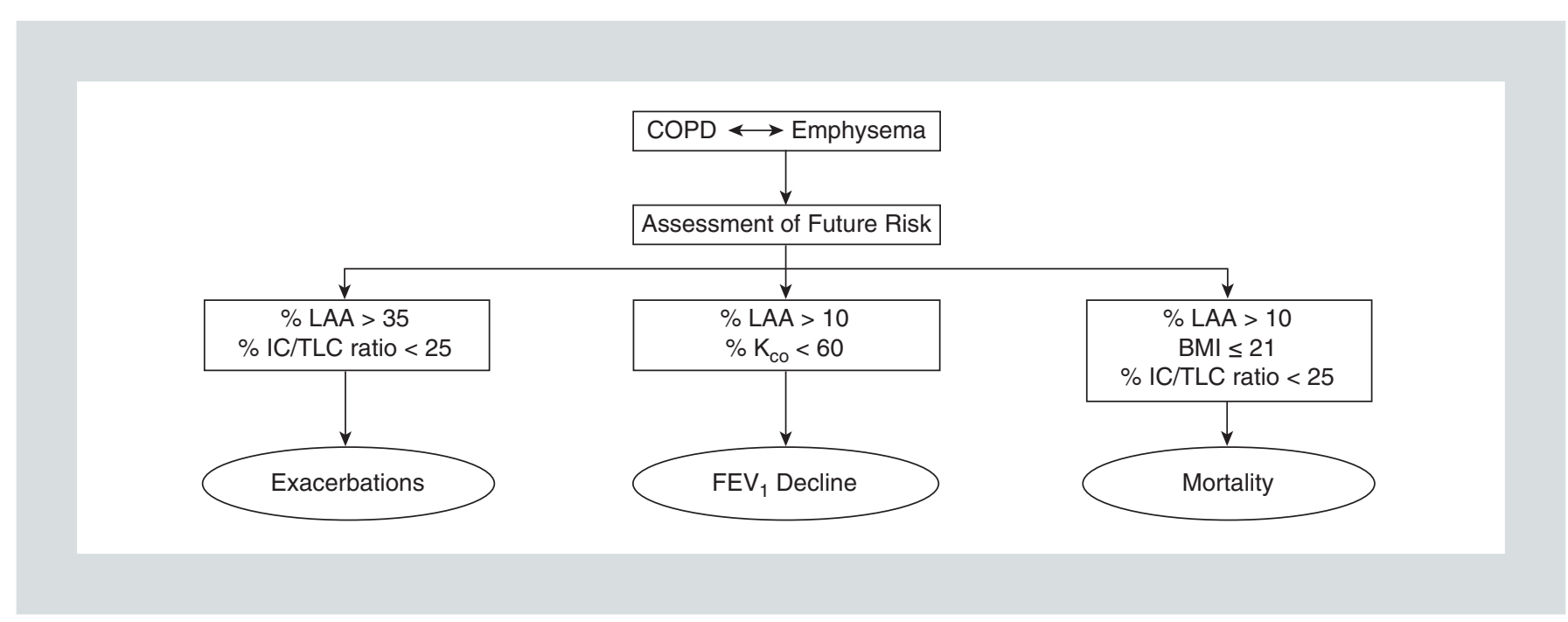

Figure 5. Parameters with their cut-off values associated with important outcomes in the natural history of chronic obstructive pulmonary disease (COPD) patients with the emphysema phenotype.

BMI: body mass index; $\mathrm{FEV}_{1}$ : forced expiratory volume in 1 secon; IC/TLC: inspiratory capacity and lung total capacity; $\mathrm{K}_{\mathrm{co}}$ : carbon monoxide transfer factor; LAA: low attenuation areas.

\section{CONFLICT OF INTEREST}

\section{Dr. Juan P. de Torres and Dr. Ciro Casanova have nothing to disclose.}

\section{REFERENCES}

1. Vogelmeier CF, Criner GJ, Martínez FJ et al. Global Strategy for the Diagnosis, Management, and Prevention of Chronic Obstructive Lung Disease 2017 Report: GOLD Executive Summary. Arch Bronconeumol. 2017;128-49.

2. The definition of emphysema. Report of a National Heart, Lung, and Blood Institute, Division of Lung Diseases workshop. Am Rev Respir Dis. 1985; 132:182-5.

3. Goddard PR, Nicholson EM, Laszlo G, Watt I. Computed tomography in pulmonary emphysema. Clin Radiol. 1982;33:379-87.

4. Madani A, Zanen J, de Maertelaer V, Gevenois PA. Pulmonary emphysema: objective quantification at multi-detector row CT-comparison with macroscopic and microscopic morphometry. Radiology. 2006;238:1036-43.

5. Gould GA, Redpath AT, Ryan M et al. Lung CT density correlates with measurements of airflow limitation and the diffusing capacity. Eur Respir J. 1991;4:141-6.

6. Martinez FJ, Flaherty KR, Iannettoni MD. Patient selection for lung volume reduction surgery. Chest Surg Clin N Am. 2003;13:669-85.

7. Stockley RA, Miravitlles M, Vogelmeier C; Alpha One International Registry (A.I.R.). Augmentation therapy for alpha- 1 antitrypsin deficiency: towards a personalised approach. Orphanet J Rare Dis. 2013;8:149.

8. Nakano Y, Coxson HO, Bosan S et al. Core to rind distribution of severe emphysema predicts outcome of lung volume reduction surgery. Am J Respir Crit Care Med. 2001;164:2195-9.

9. Mair G, Miller JJ, McAllister D et al. Computed tomographic emphysema distribution: relationship to clinical features in a cohort of smokers. Eur Respir J. 2009;33:536-42.
10. de Torres JP, Bastarrika G, Zagaceta J et al. Emphysema presence, severity, and distribution has little impact on the clinical presentation of a cohort of patients with mild to moderate COPD. Chest. 2011;139:36-42.

11. Tan WC, Hague CJ, Leipsic J, Bourbeau J et al. Findings on Thoracic Computed Tomography Scans and Respiratory Outcomes in Persons with and without Chronic Obstructive Pulmonary Disease: A Population-Based Cohort Study. PLoS One. 2016;11:e0166745.

12. Klooster K, ten Hacken NH, Hartman JE, Sciurba FC, Kerstjens HA, Slebos DJ Determining the Role of Dynamic Hyperinflation in Patients with Severe Chronic Obstructive Pulmonary Disease. Respiration. 2015;90:306-13.

13. Watz H, Waschki B, Meyer T et al. Decreasing cardiac chamber sizes and associated heart dysfunction in COPD: role of hyperinflation. Chest. 2010 138:32-8.

14. Vassaux C, Torre-Bouscoulet L, Zeineldine S et al. Effects of hyperinflation on the oxygen pulse as a marker of cardiac performance in COPD. Eur Respir J. 2008;32:1275-82.

15. Come CE, Divo MJ, San José Estépar R et al. Lung deflation and oxygen pulse in COPD: results from the NETT randomized trial. Respir Med. 2012;106:109-19.

16. Teopompi E, Tzani P, Aiello M et al. Fat-free mass depletion is associated with poor exercise capacity irrespective of dynamic hyperinflation in COPD patients. Respir Care. 2014;59:718-25.

17. de Torres JP, Bastarrika G, Wisnivesky JP et al. Assessing the relationship between lung cancer risk and emphysema detected on low-dose CT of the chest. Chest. 2007;132:1932-8.

18. Wilson DO, Weissfeld JL, Balkan A et al. Association of radiographic emphysema and airflow obstruction with lung cancer. Am J Respir Crit Care Med. 2008;178:738-44.

19. de-Torres JP, Casanova C, Marín JM et al. Exploring the impact of screening with low-dose CT on lung cancer mortality in mild to moderate COPD patients: a pilot study. Respir Med. 2013;107:702-7.

20. Houghton AM. Mechanistic links between COPD and lung cancer. Nat Rev Cancer. 2013;13:233-45

21. de-Torres JP, Wilson DO, Sanchez-Salcedo P et al. Lung Cancer in Patients with Chronic Obstructive Pulmonary Disease. Development and Validation of the COPD Lung Cancer Screening Score. Am J Respir Crit Care Med. 2014;191:285-91. 
22. de-Torres JP, Marín JM, Casanova C et al. Identification of COPD patients at high risk for lung cancer mortality using the COPD-LUCSS-DLCO. Chest. 2015;149:936-42.

23. Ciba Guest Symposium. Terminology, definitions and classifications of chronic pulmonary emphysema and related conditions. Thorax. 1959;14: 286-99.

24. Kurosaki H, Ishii T, Motohashi $\mathrm{N}$ et al. Extent of emphysema on HRCT affects loss of fat-free mass and fat mass in COPD. Intern Med. 2009;48:41-8.

25. Mineo D, Ambrogi V, Lauriola V, Pompeo E, Mineo TC. Recovery of body composition improves long-term outcomes after lung volume reduction surgery for emphysema. Eur Respir J. 2010;36:408-16.

26. Romme EA, Smeenk FW, Rutten EP, Wouters EF. Osteoporosis in chronic obstructive pulmonary disease. Expert Rev Respir Med. 2013;7:397-410.

27. Bon J, Fuhrman CR, Weissfeld JL et al. Radiographic emphysema predicts low bone mineral density in a tobacco-exposed cohort. Am J Respir Crit Care Med. 2011;183:885-90.

28. Bai P, Sun Y, Jin J, Hou J, Li R, Zhang Q, Wang Y. Disturbance of the OPG/ RANK/RANKL pathway and systemic inflammation in COPD patients with emphysema and osteoporosis. Respir Res. 2011;12:157.

29. Casanova C, de Torres JP, Aguirre-Jaíme A et al. The Progression of Chronic Obstructive Pulmonary Disease is Heterogeneous: The Experience of the BODE Cohort. Am J Respir Crit Care Med. 2011;184:1015-21.

30. Nishimura M, Makita H, Nagai K, et al. Annual change in pulmonary function and clinical phenotype in chronic obstructive pulmonary disease. Am J Respir Crit Care Med. 2012;185:44-52.

31. Vestbo J, Edwards LD, Scanlon PD et al. Changes in forced expiratory volume in 1 second over time in COPD. N Engl J Med. 2011; 365:1184-92.

32. de Torres JP, Marín JM, Pinto-Plata V et al. Is COPD a Progressive Disease? A Long Term BODE Cohort Observation. PLoS One. 2016;11:e0151856.

33. Lange P, Celli B, Agustí A et al. Lung-Function Trajectories Leading to Chronic Obstructive Pulmonary Disease. N Engl J Med. 2015; 373:111-22.

34. Miravitlles M, Soler-Cataluña JJ, Calle M et al. Spanish Guidelines for Management of Chronic Obstructive Pulmonary Disease (GesEPOC) 2017. Pharmacological Treatment of Stable Phase. Arch Bronconeumol 2017;53: 324-35.

35. Galbán CJ, Han MK, Boes JL et al. Computed tomography-based biomarker provides unique signature for diagnosis of COPD phenotypes and disease progression. Nat Med. 2012;18:1711-5.

36. Faner R, Cruz T, Casserras T et al. Network Analysis of Lung Transcriptomics Reveals a Distinct B Cell Signature in Emphysema. Am J Respir Crit Care Med. 2016;193:1242-53.

37. Tanabe N, Muro S, Tanaka S et al. Emphysema distribution and annual changes in pulmonary function in male patients with chronic obstructive pulmonary disease. Respir Res. 2012; 13: 31.

38. Lee JS, Kim SO, Seo JB et al. Longitudinal lung volume changes in patients with chronic obstructive pulmonary disease. Lung. 2013;191:405-12.

39. Park J, Lee $\mathrm{CH}$, Lee $\mathrm{YJ}$ et al. Longitudinal changes in lung hyperinflation in COPD. Int J Chron Obstruct Pulmon Dis. 2017;12:501-8.

40. Gurney JW, Jones KK, Robbins RA et al. Regional distribution of emphysema: correlation of high-resolution CT with pulmonary function tests in unselected smokers. Radiology. 1992;183:457-63.

41. Saitoh T, Koba H, Shijubo N, Tanaka H, Sugaya F. Lobar distribution of emphysema in computed tomographic densitometric analysis. Invest Radiol. 2000;35:235-43.

42. Landbo C, Prescott E, Lange P, Vestbo J, Almdal TP. Prognostic value of nutritional status in chronic obstructive pulmonary disease. Am J Respir Crit Care Med. 1999;160:1856-61.

43. Hurst JR, Vestbo J, Anzueto A et al. Susceptibility to exacerbation in chronic obstructive pulmonary disease. Evaluation of COPD Longitudinally to
Identify Predictive Surrogate Endpoints (ECLIPSE) Investigators. N Engl J Med. 2010;363:1128-38.

44. Han MK, Kazerooni EA, Lynch DA et al. Chronic obstructive pulmonary disease exacerbations in the COPDGene study: associated radiologic phenotypes. Radiology. 2011;261:274-82.

45. Zaman M, Mahmood S, Altayeh A. Low inspiratory capacity to total lung capacity ratio is a risk factor for chronic obstructive pulmonary disease exacerbation. Am J Med Sci. 2010;339:411-4.

46. Oh YM, Sheen SS, Park JH, et al. Emphysematous phenotype is an independent predictor for frequent exacerbation of COPD. Int J Tuberc Lung Dis. 2014;18:1407-14.

47. Washko GR, Fan VS, Ramsey SD et al. The effect of lung volume reduction surgery on chronic obstructive pulmonary disease exacerbations. Am Respir Crit Care Med. 2008;177:164-9.

48. Tanabe N, Muro S, Hirai T et al. Impact of exacerbations on emphysema progression in chronic obstructive pulmonary disease. Am J Respir Crit Care Med. 2011;183:1653-9.

49. Coxson HO, Dirksen A, Edwards LD et al. The presence and progression of emphysema in COPD as determined by CT scanning and biomarker expression: a prospective analysis from the ECLIPSE study. Lancet Respir Med. 2013;1:129-36.

50. Celli BR, Cote C, Marin JM et al. The Body Mass Index, Airflow Obstruction, Dyspnoea, Exercise Performance (BODE) Index in Chronic Obstructive Pulmonary Disease. N Engl J Med. 2004;350:1005-12.

51. Casanova C, Cote C, de Torres JP et al. The inspiratory to total lung capacity ratio predicts mortality in patients with COPD. Am J Respir Crit Care Med. 2005;171:591-7.

52. Martinez FJ, Foster G, Curtis JL et al. Predictors of mortality in patients with emphysema and severe airflow obstruction. Am J Respir Crit Care Med. 2006;173:1326-34.

53. Tanabe N, Vasilescu DM, McDonough JE et al. Micro-Computed Tomography Comparison of Preterminal Bronchioles in Centrilobular and Panlobular Emphysema. Am J Respir Crit Care Med. 2017;195:630-8.

54. Haruna A, Muro S, Nakano Y et al. CT scan findings of emphysema predict mortality in COPD. Chest. 2010;138:635-40.

55. Johannessen A, Skorge TD, Bottai M et al. Mortality by level of emphysema and airway wall thickness. Am J Respir Crit Care Med. 2013;187:602-8.

56. Ishii T, Hagiwara K, Kamio K et al. Involvement of surfactant protein D in emphysema revealed by genetic association study. Eur J Hum Genet. 2012; 20:230-5.

57. Parr DG, White AJ, Bayley DL, Guest PJ, Stockley RA. Inflammation in sputum relates to progression of disease in subjects with COPD: a prospective descriptive study. Respir Res. 2006;7:136.

58. Hogg JC, Timens W. The pathology of chronic obstructive pulmonary disease. Annu Rev Pathol. 2009;4:435-59.

59. Barr RG, Bluemke DA, Ahmed FS et al. Percent emphysema, airflow obstruction, and impaired left ventricular filling. N Engl J Med. 2010;362:217-27.

60. Barr RG. The epidemiology of vascular dysfunction relating to chronic obstructive pulmonary disease and emphysema. Proc Am Thorac Soc. 2011; 8:522-7.

61. Divo M, Cote C, de Torres JP et al. Comorbidities and risk of mortality in patients with chronic obstructive pulmonary disease. Am J Respir Crit Care Med. 2012;186:155-61.

62. de-Torres JP, Blanco D, Alcaide AB et al. Smokers with CT detected emphysema and no airway obstruction have decreased plasma levels of EGF IL-15, IL-8 and IL-1ra. PLoS One. 2013;8:e60260.

63. Alcaide AB, Sanchez-Salcedo P, Bastarrika G et al. Clinical Features of Smokers With Radiological Emphysema But Without Airway Limitation. Chest. 2017;151:358-65. 